Cite this article as: BMJ, doi:10.1136/bmj.38875.675486.55 (published 21 June 2006)

Research

\title{
A meta-analysis of the association between adherence to drug therapy and mortality
}

Scot H Simpson, Dean T Eurich, Sumit R Majumdar, Rajdeep S Padwal, Ross T Tsuyuki, Janice Varney, Jeffrey A Johnson

\begin{abstract}
Objective To evaluate the relation between adherence to drug therapy, including placebo, and mortality.

Design Meta-analysis of observational studies.

Data sources Electronic databases, contact with investigators, and textbooks and reviews on adherence.

Review methods Predefined criteria were used to select studies reporting mortality among participants with good and poor adherence to drug therapy. Data were extracted for disease, drug therapy groups, methods for measurement of adherence rate, definition for good adherence, and mortality.

Results Data were available from 21 studies (46 847

participants), including eight studies with placebo arms (19 633 participants). Compared with poor adherence, good adherence was associated with lower mortality (odds ratio $0.56,95 \%$ confidence interval 0.50 to 0.63 ). Good adherence to placebo was associated with lower mortality $(0.56,0.43$ to 0.74$)$, as was good adherence to beneficial drug therapy $(0.55,0.49$ to 0.62$)$. Good adherence to harmful drug therapy was associated with increased mortality $(2.90,1.04$ to 8.11$)$.

Conclusion Good adherence to drug therapy is associated with positive health outcomes. Moreover, the observed association between good adherence to placebo and mortality supports the existence of the "healthy adherer" effect, whereby adherence to drug therapy may be a surrogate marker for overall healthy behaviour.
\end{abstract}

\section{Introduction}

About one in four people do not adhere well to prescribed drug therapy. ${ }^{1}$ Following principles of evidence based medicine, clinicians use the most relevant and available evidence to guide decisions on drug therapy. Once the prescription is written, however, the fate of drug therapy is with the patient. Poor adherence is considered a critical barrier to treatment success and remains one of the leading challenges to healthcare professionals. ${ }^{2}$

Much of the literature on adherence focuses on methods for measuring adherence and identification of risk factors for poor adherence, ${ }^{3-6}$ with the premise that good adherence must be associated with good health outcomes. ${ }^{7}$ Although the most detailed systematic review on adherence in the literature included a wide array of disease states, drug therapy was only one element within a range of therapeutic interventions. ${ }^{7}$ Combining adherence to drug therapy with adherence to other behavioural and therapeutic interventions limits the ability to examine specifically the relation between adherence to drug therapy and health outcomes.
Ideally the effect of adherence should be measured on an objective health outcome, such as mortality. Individual studies have reported that good adherence to prescribed drug therapyeven to placebo-was associated with a lower risk of mortality. ${ }^{\mathrm{w1}-\mathrm{w} 3}$ This is contrary to the proposition that a placebo has little effect on health outcomes ${ }^{8}$ and has led to speculation that adherence to drug therapy may act as an identifiable marker for overall healthy behaviour, the so called healthy adherer effect. ${ }^{\mathrm{w}-\mathrm{w} 4}{ }^{8-10} \mathrm{We}$ tested this hypothesis by summarising published observations of the relation between adherence to drug therapy and mortality, with a particular interest in placebo arms of controlled studies.

\section{Methods}

We used standard systematic review methods. ${ }^{11}$ Eligible for inclusion in our study were randomised controlled trials, retrospective analyses of data from randomised controlled trials, and observational studies evaluating the association between adherence to drug therapy and mortality. We applied no language restrictions.

A professional librarian (JV) carried out the literature search. She searched several electronic databases from inception date to 20 June 2005: Allied and Complementary Medicine (AMED), Cumulative Index to Nursing and Allied Health Literature (CINAHL), Embase, Educational Research Information Center (ERIC), HealthSTAR, Medline, PsycINFO, and the Web of Science. Articles were identified using synonyms for adherence and mortality as database specific subject headings and keywords. We also checked references from textbooks ${ }^{12-14}$ and review articles ${ }^{17} 9_{10}^{15-17}$ on adherence for additional articles.

After excluding editorials, conference proceedings, letters, news articles, government reports, and practice guidelines, two investigators (SHS, DTE) independently screened titles and abstracts to identify potentially relevant citations. A citation was retained for further evaluation if either investigator selected it. Citations were excluded that did not report original data, have human participants, evaluate drug adherence, or report patient adherence.

Each potentially relevant article was reviewed to determine if it met the following inclusion criteria: described original research, explained the method used to measure adherence (for example, self report, electronic drug event monitoring system, pharmacy refill data, clinician estimation, tablet count), provided a clear definition for good adherence, stratified patients into good and poor adherence groups, and reported mortality

Web references w1-w22 and author details are on bmj.com 
according to adherence groups. Discrepancies were resolved by majority vote after review by a third investigator (JAJ).

Inter-reviewer agreement was measured during the initial screen to identify potentially relevant citations and on review of the full articles for study inclusion. ${ }^{18}$ We characterised level of agreement using a qualitative scale developed by Landis and Koch. ${ }^{19}$

\section{Data collection and outcome measures}

Two investigators (DTE, RSP) used standardised forms to extract data from the included articles for disease state, drug therapy groups, methods used to measure adherence, definition for good adherence, and mortality. Accuracy of data collection was verified by comparing forms. We used the study authors' definition to stratify participants into good and poor adherence groups. When the number of deaths according to adherence group was not specifically stated in the article, we calculated this value from available information. If there was insufficient information in the article to calculate mortality according to adherence group, we contacted the corresponding author. The study was excluded if we were unable to obtain from the authors the number of deaths in each adherence group.

\section{Statistical analysis}

We analysed data using Rev Man 4.2.7. Each treatment arm in a randomised controlled trial was considered a discrete analysis of the relation between adherence and mortality. We used a random effects model to calculate pooled odds ratios and 95\% confidence intervals. ${ }^{20}$ Given the inclusion criteria, we anticipated including studies of a variety of diseases; therefore we examined heterogeneity using the $\mathrm{Q}$ and $\mathrm{I}^{2}$ statistics. ${ }^{20}{ }^{21}$ We used a variation of Tobias' method to evaluate changes to the pooled odds ratio and tests for heterogeneity. ${ }^{22}$ Rather than removing one study at a time, we used predetermined subgroups to identify potential sources of heterogeneity. For example, to test the theory of a healthy adherer effect, ${ }^{\text {w1-w4 }}{ }^{8-10}$ we constructed a separate model to summarise the association between adherence to placebo and mortality. A priori subgroups included the effect of active treatment compared with placebo, study design, disease state, method used to measure adherence, and definition for good adherence.

\section{Results}

Overall, 6231 unique citations were identified and 1140 ones related to non-studies were removed. In total, 5012 citations were excluded after review of the title and abstract (fig 1). Agreement to identify potentially relevant articles was 0.68 , which is considered "substantial." ${ }^{19}$ From the 79 potentially relevant articles, 21 studies with 46847 participants met the inclusion criteria. ${ }^{\text {w1-w21 }}$ Agreement at this stage was 0.97 , considered "almost perfect."19

Supplemental information on mortality was obtained from multiple sources for some studies. In the University Group Diabetes Program, mortality for participants with good adherence was available in a paper on statistical methods. ${ }^{\text {w18 }{ }^{\text {w22 }}}$ Supplemental mortality data according to adherence group were obtained from five corresponding authors. ${ }^{\mathrm{w} 5 \mathrm{w} / \mathrm{w} 9 \mathrm{w} 10 \mathrm{w15}}$

Eight studies were randomised, placebo controlled trials (37 701 participants) reporting mortality according to adherence group for each treatment arm in a retrospective analysis. ${ }^{\mathrm{w}-\mathrm{w} 4}$ w8 w16-w18 w22 Thirteen cohort studies (9146 participants) reported mortality according to adherence groups. ${ }^{\text {w5-w7 }{ }^{\mathrm{w} 9-\mathrm{w} 15} \text { w19-w21 }}$ Table 1 lists the characteristics of the included studies. Eight studies evaluated drug therapy in participants with a recent myocardial infarction, ${ }^{\mathrm{w} 1-\mathrm{w} 8}$ seven studies were in patients infected with HIV, ${ }^{\text {w9- }}$ ${ }_{w 15}$ and two studies were in primary prevention of heart disease. ${ }^{\text {w16 }}$ w17 The remaining studies evaluated adherence to drug therapy for patients with type 2 diabetes, ${ }^{\mathrm{w} 18}{ }^{\mathrm{w} 22}$ hyperlipidaemia, ${ }^{\text {w19 }}$ heart failure, ${ }^{\mathrm{w} 20}$ and immune suppression after heart transplant. ${ }^{\mathrm{w} 21}$ Fifteen studies reported an adherence rate threshold to define good adherence. ${ }^{\mathrm{w1}-\mathrm{w} 5}$ w7 $\mathrm{w} 8 \mathrm{w11}$ w13-w19 w22 All cause mortality was the primary outcome in nine studies ${ }^{\mathrm{w} 2}$ w3 $\mathrm{w} 9 \mathrm{w}-\mathrm{w} 13 \mathrm{w} 15 \mathrm{w} 19$ and a secondary

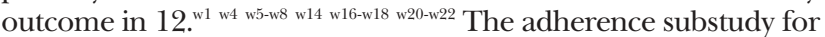
the cardiac arrhythmia suppression trial reported arrhythmic mortality according to adherence group. ${ }^{\mathrm{w} 4}$ Although $67 \%$ of the deaths in this trial were attributable to an arrhythmia, data for all cause mortality were not available. ${ }^{\mathrm{w4}} 23$

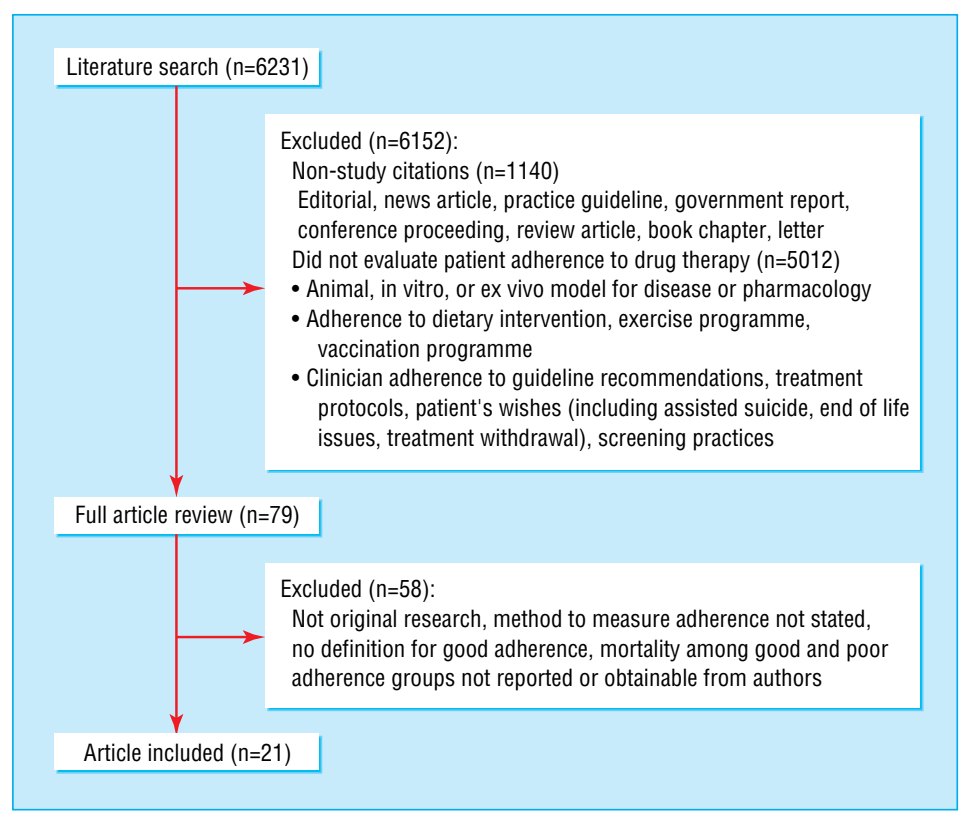

Fig 1 Flow of articles identified and studies included in review 
Research

Table 1 Characteristics of included studies in meta-analysis of adherence to drug therapy and mortality

\begin{tabular}{|c|c|c|c|c|c|}
\hline Study & Study type & Treatment groups (No of participants) & Adherence measures & $\begin{array}{l}\text { Threshold for good } \\
\text { adherence }\end{array}$ & Observation period \\
\hline \multicolumn{6}{|l|}{$\begin{array}{l}\text { Post-myocardial infarction } \\
\text { management: }\end{array}$} \\
\hline $\begin{array}{l}\text { Coronary Drug Project Research } \\
\text { Group } 1980^{\text {w1 }}\end{array}$ & Randomised controlled trial & Placebo (2695), clofibrate (1065) & $\begin{array}{l}\text { Pill count, clinician's } \\
\text { impression }\end{array}$ & $\geq 80 \%$ & $\geq 5$ years \\
\hline Wei et al $2002^{\text {w5 }}$ & Cohort & Statins (427) & Pharmacy refill & $\geq 80 \%$ & Average 2.4 years \\
\hline Cotter et al 2004 $4^{w 6}$ & Cohort & Acetylsalicylic acid (64) & Thromboxane blood level & $\begin{array}{l}\text { Less than healthy } \\
\text { volunteer }\end{array}$ & 1 year \\
\hline $\begin{array}{l}\beta \text { blocker heart attack trial (men) } \\
1990^{\text {w2 }}\end{array}$ & Randomised controlled trial & Placebo (1094), propranolol (1081) & Pill count & $>75 \%$ & 1 year \\
\hline $\begin{array}{l}\beta \text { blocker heart attack trial } \\
\text { (women) } 1993^{\text {w3 }}\end{array}$ & Randomised controlled trial & Placebo (240), propranolol (265) & Pill count & $\geq 75 \%$ & Median 26 months \\
\hline Wei et al $2004^{w 7}$ & Cohort & $\beta$ blockers (386) & Pharmacy refill & $\geq 80 \%$ & Median 3.7 years \\
\hline $\begin{array}{l}\text { Canadian amiodarone myocardial } \\
\text { infarction arrhythmia trial } 1999^{\text {w8 }}\end{array}$ & Randomised controlled trial & Placebo (538), amiodarone (573) & Pill count & $\geq 66 \%$ & 2 years \\
\hline $\begin{array}{l}\text { Cardiac arrhythmia suppression } \\
\text { trial } 1996^{\mathrm{w4}}\end{array}$ & Randomised controlled trial & $\begin{array}{l}\text { Placebo (579), encainide or flecainide } \\
\text { (574) }\end{array}$ & Pill count & $>80 \%$ & Average 10 months \\
\hline \multicolumn{6}{|l|}{ HIV infection: } \\
\hline San Andres Rebollo et al $2004^{\text {w9 }}$ & Cohort & Antiretroviral therapy (950) & Self report & Continued use & 8 years \\
\hline Cohn et al $2002^{w 10}$ & Cohort & Antiretroviral therapy (626) & Self report & $\begin{array}{l}\text { No missed doses in } \\
\text { previous } 48 \text { hours }\end{array}$ & 56 weeks \\
\hline Garcia de Olalla et al $2002^{w 11}$ & Cohort & Antiretroviral therapy (1219) & $\begin{array}{l}\text { Self report and pharmacy } \\
\text { refill }\end{array}$ & $\geq 90 \%$ & 3 years \\
\hline Grimwade et al $2005^{\mathrm{w} 12}$ & Cohort & Cotrimoxazole prophylaxis (1288) & $\begin{array}{l}\text { Self report and frequency } \\
\text { of clinic visits }\end{array}$ & $\begin{array}{l}\text { Continued use, collection } \\
\text { of new tablet supply, and } \\
\text { ongoing attendance at } \\
\text { clinic }\end{array}$ & 6 months \\
\hline Hogg et al $2002^{w 13}$ & Cohort & Antiretroviral therapy (1282) & Pharmacy refill & $\geq 75 \%$ & 1 year \\
\hline Paterson et al $2000^{w 14}$ & Cohort & Protease inhibitors (81) & $\begin{array}{l}\text { Medication event } \\
\text { monitoring system }\end{array}$ & $\geq 95 \%$ & Median 6 months \\
\hline Wood et al $2003^{\text {w15 }}$ & Cohort & Antiretroviral therapy (1422) & Pharmacy refill & $\geq 75 \%$ & 4 years \\
\hline \multicolumn{6}{|l|}{$\begin{array}{l}\text { Primary prevention of cardiovascular } \\
\text { disease: }\end{array}$} \\
\hline Physicians' health study $1994^{\text {w16 }}$ & Randomised controlled trial & $\begin{array}{l}\text { Placebo (10 989), acetylsalicylic acid } \\
\text { (11 004) }\end{array}$ & Self report & $\geq 95 \%$ & Average 60.2 months \\
\hline $\begin{array}{l}\text { West of Scotland prevention study } \\
1997^{\text {w17 }}\end{array}$ & Randomised controlled trial & Placebo (3293), pravastatin (3302) & Pill count & $\geq 75 \%$ & Mean 4.9 years \\
\hline \multicolumn{6}{|l|}{ Other disease states: } \\
\hline $\begin{array}{l}\text { University Group Diabetes Project } \\
1970^{\text {w22 }} 1971^{\text {w18 }} \text { (type } 2 \text { diabetes) }\end{array}$ & Randomised controlled trial & Placebo (205), tolbutamide (204) & Clinician's impression & $\geq 75 \%$ & $\begin{array}{l}\geq 75 \% \text { followed for } \geq 5 \\
\text { years }\end{array}$ \\
\hline $\begin{array}{l}\text { Howell et al } 2004^{\text {w19 }} \\
\text { (hypercholesterolaemia) }\end{array}$ & Cohort & Statins (869) & Pharmacy refill & $\geq 80 \%$ & 11 years \\
\hline Miura et al $2001^{\mathrm{w} 20}$ (heart failure) & Cohort & Digoxin (431) & Blood levels of drug & Therapeutic range & 72 months \\
\hline $\begin{array}{l}\text { Dobbels et al 2004 } \\
\text { transplant) }\end{array}$ & Cohort & Immunosuppressive regimen(101) & $\begin{array}{l}\text { Medication event } \\
\text { monitoring system (for } \\
\text { cyclosporin use) }\end{array}$ & $\begin{array}{l}\text { No variation in dose } \\
\text { compliance and no drug } \\
\text { holidays }\end{array}$ & 5 years \\
\hline
\end{tabular}

The primary analysis of mortality risk according to adherence group was based on 2779 (5.9\%) deaths in 46847 participants. Overall, 1462 (4.7\%) deaths occurred in 31439 participants with good adherence to drug therapy and 1317 (8.5\%) deaths in 15408 participants considered to have poor adherence. The pooled odds ratio for mortality for good adherence compared with poor adherence was 0.56 (95\% confidence interval 0.50 to 0.63$)$. Some degree of heterogeneity was found: $Q$ statistic $\mathrm{P}=0.08$ and $\mathrm{I}^{2}=28.6 \%$.

The placebo arms from eight studies contained 19633 participants and reported 996 (5.1\%) deaths. ${ }^{\text {w1-w4 w8 w16-w18 w22 }}$ Overall, good adherence to placebo was associated with a lower risk of mortality: pooled odds ratio $0.56,0.43$ to 0.74 (fig 2). Some heterogeneity of effect was found in this analysis: $Q$ statistic $P=0.05$ and $\mathrm{I}^{2}=51.2 \%$. A subgroup analysis restricted to studies of drug therapy after myocardial infarction reduced variance substantially: $\mathrm{Q}$ statistic $\mathrm{P}=0.79$ and $\mathrm{I}^{2}=0 \%{ }^{\mathrm{w} 1{ }^{1-\mathrm{w} 4} \mathrm{w} 8}$ The pooled odds ratio of these five studies was 0.45 ( 0.38 to 0.54 ).

Two studies were identified in which active drug therapy increased the risk of mortality compared with placebo. ${ }^{22}{ }_{23}$ Therefore separate models were constructed to summarise the effect of adherence to active drug therapy found to be harmful compared with beneficial (fig 3). The two studies evaluating adherence to harmful drug therapy reported $53(6.8 \%)$ deaths in 778 participants. $^{\mathrm{w} 4 \mathrm{w} 18 \mathrm{w} 22}$ The pooled odds ratio for mortality was 2.90 (1.04 to 8.11) for participants with good compared with poor adherence to the active treatment (fig 3).

The association between adherence to proved beneficial drug therapy and mortality was reported in 19 studies involving 26436 participants and $1730(6.5 \%)$ deaths. ${ }^{\text {w1-w3 }}{ }^{\text {w5-w17 } 1919-{ }^{-w 21}}$ The pooled odds ratio from these studies was 0.55 (0.49 to 0.62$)$ for mortality in participants with good adherence compared with poor adherence (fig 3). These observations were homogeneous ( $Q$ statistic $\mathrm{P}=0.71$ and $\mathrm{I}^{2}=0 \%$ ) and further stratification by study characteristics did not result in substantive changes to these relations (table 2). However, moderate variance of the observed effects was found among the seven HIV studies $\left(\mathrm{I}^{2}=50.2 \%\right)$ and among the four studies that used subjective methods to measure adherence $\left(\mathrm{I}^{2}=61.0 \%\right){ }^{21}$ Minor variance $\left(\mathrm{I}^{2}=8.6 \%\right)$ was found among the 13 cohort studies (table 2$){ }^{21}$ 


\section{Discussion}

This meta-analysis of 21 studies, involving 46847 participants, showed a consistent association between adherence to drug therapy and mortality. For participants with good adherence to placebo or beneficial drug therapy, the risk of mortality was about half that of participants with poor adherence. Conversely, the risk of mortality was more than doubled for participants with good adherence to proved harmful drug therapy compared with participants with poor adherence.

\begin{tabular}{|c|c|c|c|c|c|c|c|}
\hline Study & $\begin{array}{l}\text { Good adherence } \\
\text { to drug therapy }\end{array}$ & $\begin{array}{l}\text { Poor adherence } \\
\text { to drug therapy }\end{array}$ & \multicolumn{3}{|c|}{$\begin{array}{c}\text { Odds ratio (random) } \\
(95 \% \mathrm{Cl})\end{array}$} & $\begin{array}{c}\text { Weight } \\
(\%)\end{array}$ & $\begin{array}{c}\text { Odds ratio (random) } \\
(95 \% \mathrm{CI})\end{array}$ \\
\hline Coronary Drug Project Research Group $1980^{\text {w1 }}$ & $274 / 1813$ & $249 / 882$ & $\rightarrow$ & & & 27.53 & $0.45(0.37$ to 0.55$)$ \\
\hline$\beta$ blocker heart attack trial (men) $1990^{\text {w2 }}$ & $31 / 1037$ & $4 / 57$ & - & - & & 5.11 & $0.41(0.14$ to 1.20$)$ \\
\hline$\beta$ blocker heart attack trial (women) $1993^{\text {w3 }}$ & $15 / 219$ & $4 / 21$ & $\longleftrightarrow$ & - & & 4.20 & $0.31(0.09$ to 1.05$)$ \\
\hline Canadian amiodarone myocardial infarction arrhythmia trial $1999^{\text {w8 }}$ & $42 / 447$ & $17 / 91$ & $\longrightarrow$ & & & 11.81 & $0.45(0.24$ to 0.84$)$ \\
\hline Cardiac arrhythmia suppression trial $1996^{\text {w4 }}$ & $8 / 486$ & $1 / 93$ & & $\rightarrow$ & $\longrightarrow$ & 1.54 & $1.54(0.19$ to 12.46$)$ \\
\hline Physicians health study $1994^{\text {w16 }}$ & $105 / 6864$ & $90 / 4125$ & & & & 23.59 & $0.70(0.52$ to 0.93$)$ \\
\hline West of Scotland prevention study $1997^{\text {w17 }}$ & $95 / 2420$ & $40 / 873$ & & + & & 19.54 & 0.85 (0.58 to 1.24$)$ \\
\hline University Group Diabetes Project $1970{ }^{\text {w22 }} 1971^{\text {w18 }}$ & $11 / 143$ & $10 / 62$ & 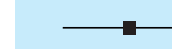 & & & 6.69 & $0.43(0.17$ to 1.08$)$ \\
\hline Total $(95 \% \mathrm{Cl})$ & 13429 & 6204 & & & & 100.00 & $0.56(0.43$ to 0.74$)$ \\
\hline Total events: 581 (good adherence), 415 (poor adherence) & & & 0.10 .2 & 2 & 10 & & \\
\hline $\begin{array}{l}\text { Test for heterogeneity: } \chi^{2}=14.34, d f=7(P=0.05), I^{2}=51.2 \% \\
\text { Test for overall effect: } Z=4.23, P<0.0001\end{array}$ & & & $\begin{array}{l}\text { od adherence to } \\
\text { ig therapy }\end{array}$ & & $\begin{array}{l}\text { Iherence to } \\
\text { rug therapy }\end{array}$ & & \\
\hline
\end{tabular}

Fig 2 Association between adherence to placebo and mortality

\section{Study \\ Harmful drug therapy}

Cardiac arrhythmia suppression trial $1996^{\text {w4 }}$ University Group Diabetes Project $1970^{\mathrm{w} 22} 1971^{\mathrm{w} 18}$

Total $(95 \% \mathrm{Cl})$

Total events: 49 (good adherence), 4 (poor adherence)

Test for heterogeneity: $\chi^{2}=0.43, \mathrm{df}=1, \mathrm{P}=0.51, I^{2}=0 \%$

Test for overall effect: $z=2.03, P=0.04$

\section{Beneficial drug therapy}

Coronary Drug Project Research Group $1980^{\text {w1 }}$

Wei et al $2002^{\text {w5 }}$

Cotter et al $2004^{\text {w6 }}$

$\beta$ blocker heart attack trial (men) $1990^{\text {w2 }}$

$\beta$ blocker heart attack trial (women) $1993^{\text {w3 }}$

Wei et al $2004^{\text {W7 }}$

Canadian amiodarone myocardial infarction arrhythmia trial 1999 w8

San Andres Rebollo et al 2004 ${ }^{\text {w9 }}$

Cohn et al $2002^{\text {w10 }}$

Garcia de Olalla et al $2002^{\text {w11 }}$

Grimwade et al $2005^{\text {w12 }}$

Hogg et al $2002^{\text {w13 }}$

Paterson et al $2000^{\text {w14 }}$

Wood et al $2003^{\text {w15 }}$

Physicians health study $1994^{\text {w16 }}$

West of Scotland prevention study $1997^{\mathrm{w} 17}$

Howell et al $2004^{\text {w19 }}$

Miura et al $2001^{\text {w20 }}$

Dobbels et al $2004^{\text {w21 }}$

Total $(95 \% \mathrm{Cl})$

Total events: 832 (good adherence), 898 (poor adherence)

Test for heterogeneity: $\chi^{2}=14.34, \mathrm{df}=18, \mathrm{P}=0.71, I^{2}=0 \%$

Test for overall effect: $z=10.54, P<0.0001$

Fig 3 Association between adherence to harmful or beneficial drug therapy and mortality

\begin{tabular}{|c|c|}
\hline $\begin{array}{l}\text { Good adherence } \\
\text { to drug therapy }\end{array}$ & $\begin{array}{l}\text { Poor adherenc } \\
\text { to drug therap }\end{array}$ \\
\hline $23 / 505$ & $0 / 69$ \\
\hline $26 / 151$ & $4 / 53$ \\
\hline 656 & 122 \\
\hline $106 / 708$ & $88 / 357$ \\
\hline $14 / 272$ & $14 / 155$ \\
\hline $1 / 52$ & $1 / 12$ \\
\hline $14 / 1009$ & $3 / 72$ \\
\hline $11 / 242$ & $2 / 23$ \\
\hline $24 / 226$ & $26 / 160$ \\
\hline $33 / 445$ & $19 / 128$ \\
\hline $69 / 197$ & $300 / 753$ \\
\hline $8 / 585$ & $2 / 41$ \\
\hline $156 / 831$ & $105 / 388$ \\
\hline $12 / 743$ & $27 / 545$ \\
\hline $62 / 955$ & $44 / 327$ \\
\hline $0 / 23$ & $1 / 58$ \\
\hline $117 / 1067$ & $76 / 355$ \\
\hline $89 / 6608$ & $102 / 4396$ \\
\hline $66 / 2435$ & $40 / 867$ \\
\hline $24 / 654$ & $14 / 215$ \\
\hline $17 / 218$ & $32 / 213$ \\
\hline $9 / 84$ & $2 / 17$ \\
\hline 17354 & 9082 \\
\hline
\end{tabular}

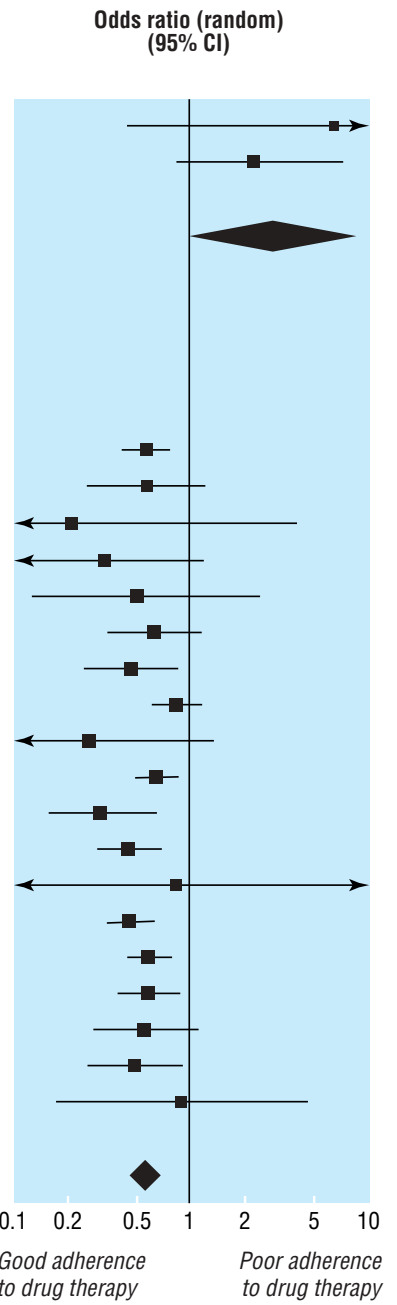

$\begin{array}{cc}\underset{(\%)}{\text { Weight }} & \text { Odds ratio (random) } \\ (95 \% \mathrm{Cl})\end{array}$

$13.34 \quad 6.77(0.41$ to 112.72$)$

$86.66 \quad 2.55(0.85$ to 7.68$)$

$100.00 \quad 2.90(1.04$ to 8.11$)$ 
Table 2 Subgroup analysis of active treatment arms considered beneficial

\begin{tabular}{|c|c|c|c|c|}
\hline \multirow[b]{2}{*}{ Analysis group } & \multirow[b]{2}{*}{$\begin{array}{l}\text { No of } \\
\text { studies }\end{array}$} & \multirow[b]{2}{*}{$\begin{array}{l}\text { Pooled odds } \\
\text { ratio (95\% CI) }\end{array}$} & \multicolumn{2}{|c|}{ Tests for heterogeneity } \\
\hline & & & $\begin{array}{l}P \text { value } \\
(Q \\
\text { statistic })\end{array}$ & $I^{2}(\%)$ \\
\hline $\begin{array}{l}\text { Active treatment arm considered } \\
\text { beneficial }\end{array}$ & 19 & $\begin{array}{c}0.55 \\
(0.49 \text { to } 0.62)\end{array}$ & 0.71 & 0 \\
\hline $\begin{array}{l}\text { Post-myocardial infarction studies } \\
\text { onlyw1'-w3 w5-w8 }\end{array}$ & 7 & $\begin{array}{c}0.52 \\
(0.41 \text { to } 0.66)\end{array}$ & 0.96 & 0 \\
\hline HIV studies only"w-w15 & 7 & $\begin{array}{c}0.53 \\
(0.41 \text { to } 0.69)\end{array}$ & 0.06 & 50.2 \\
\hline Primary prevention studies only ${ }^{\mathrm{w} 16}$ w17 & 2 & $\begin{array}{c}0.58 \\
(0.46 \text { to } 0.73)\end{array}$ & 0.99 & 0 \\
\hline \multicolumn{5}{|l|}{ Method used to measure adherence: } \\
\hline $\begin{array}{l}\text { Objective method (pill count, } \\
\text { pharmacy refill, blood level, } \\
\text { medication event monitor } \\
\text { system) } \\
\text { w1-w3 w5-w8 w11 w13-w15 w17 w19-w21 }\end{array}$ & 15 & $\begin{array}{c}0.53 \\
(0.46 \text { to } 0.60)\end{array}$ & 0.99 & 0 \\
\hline $\begin{array}{l}\text { Subjective method (patient self } \\
\text { report, clinician impression) })^{\text {w9 }} \text { w10 w12 } \\
\text { w16 }\end{array}$ & 4 & $\begin{array}{c}0.55 \\
(0.37 \text { to } 0.83)\end{array}$ & 0.05 & 61.0 \\
\hline \multicolumn{5}{|l|}{$\begin{array}{l}\text { Threshold used to define good } \\
\text { adherence group: }\end{array}$} \\
\hline$\geq 75^{\text {w1-w33 w5 w7 w11 w13-w17 w19 }}$ & 12 & $\begin{array}{c}0.54 \\
(0.48 \text { to } 0.61)\end{array}$ & 0.97 & 0 \\
\hline$\geq 80 \%$ w1 w5 w7 w11 w14 w16 w19 & 7 & $\begin{array}{c}0.58 \\
(0.50 \text { to } 0.68)\end{array}$ & 1.00 & 0 \\
\hline$\geq 90 \%$ w11 w14 w16 & 3 & $\begin{array}{c}0.60 \\
(0.49 \text { to } 0.73)\end{array}$ & 0.91 & 0 \\
\hline \multicolumn{5}{|l|}{ Study design: } \\
\hline $\begin{array}{l}\text { Randomised controlled studies } \\
\text { onlyw1-w3 w8 w16 w17 }\end{array}$ & 6 & $\begin{array}{c}0.55 \\
(0.46 \text { to } 0.65)\end{array}$ & 0.95 & 0 \\
\hline Cohort studies onlyw5-w7 w9-w15 w19-w21 & 13 & $\begin{array}{c}0.55 \\
(0.47 \text { to } 0.64)\end{array}$ & 0.36 & 8.6 \\
\hline
\end{tabular}

The association between adherence to harmful therapy and mortality is important in the light of recent issues of patient safety and post-marketing drug surveillance. Our observation suggests that stratification by adherence group may facilitate earlier identification of harmful therapies if the rate of adverse events is higher in participants with good adherence. According to the consolidated standards of reporting trials statement, investigators should, at a minimum, report the number of participants receiving the intended treatment. ${ }^{24}$ Although randomised clinical trials will often measure adherence-either through pill count from returned vials or information on frequency of refills-this information is usually reported only as an overall adherence rate..$^{25}$ Many authors have identified that an array of adherence rates can confound the association between treatment and response and substantially affect generalisability. ${ }^{25-27}$ Therefore we would encourage clinical trialists to consider reporting treatment effects stratified by adherence group.

In 1997 McDermott and colleagues reviewed the literature on cardiovascular disease that reported admission to hospital and mortality according to adherence groups. ${ }^{9}$ They found that seven of 12 studies had a significant association between adherence and outcomes and noted that adherence to placebo was associated with improved outcomes in three studies. More recently DiMatteo and colleagues determined that the risk of a poor health outcome was $26 \%$ lower in participants with good adherence. ${ }^{7}$ Although that meta-analysis included studies from a wide range of medical conditions, drug therapy was included with a variety of other healthcare interventions. In addition, the placebo arms from controlled trials were excluded from their analysis. Our study confirms, updates, and extends these observations by including studies from across several disease states and summarises the observations between adherence to drug therapy (both active drug and placebo) and mortality.
Our study shares limitations inherent with meta-analyses in general and with studies of adherence specifically. Firstly, important studies relevant to the research question may have been missed during the literature search, although this was unlikely. Secondly, as with previous reviews, ${ }^{79}$ our data sources were observational studies, thus restricting our ability to explore fully the influence of unmeasured confounding variables. For example, participants with good adherence to study drugs (even placebo) may also have good adherence to other healthy behaviours such as diet, exercise, regular follow-up with healthcare professionals, immunisations, screening, and use of other drugs. ${ }^{\mathrm{w1}-\mathrm{w} 4}{ }^{8-10}$ All of these could independently affect the risk of mortality. Conversely, participants with poor adherence may have consciously chosen to use a lower dosage ${ }^{28} 29$ or have other conditions, such as depression, that affect adherence. ${ }^{10}{ }^{30}$ In the absence of individual patient data to control for these factors, we tested the healthy adherer effect hypothesis and assumed that the presence of good adherence is a marker for overall healthy behaviour. ${ }^{\text {w1-w4 }}{ }^{8-10}$ Thirdly, in the absence of an ideal method to measure adherence, ${ }^{31}$ we observed a wide variety of measurement methods and definitions for good adherence. Grouping studies according to measurement method and definition for good adherence did not, however, result in substantive changes to our overall observation. Finally, with the exception of two studies, ${ }^{\mathrm{w} 6}{ }^{\mathrm{w} 20}$ all studies used indirect methods to measure adherence. These methods are limited by the assumption that drug acquisition is a reasonable surrogate for consumption. This assumption would, however, overestimate exposure and bias our observation towards the null.

With these limitations in mind, our findings support the tenet that good adherence to drug therapy is associated with positive health outcomes. Moreover, the observed association between good adherence to placebo and lower mortality also supports the existence of the healthy adherer effect, whereby adherence to drug therapy may be a surrogate marker for overall healthy behaviour. Our findings set the stage for future studies to address the causal relation between adherence and health outcomes, but, more importantly, quantify for patients and providers how important it is to take drugs of proved efficacy as prescribed.

We thank the individual trialists for providing information from their study databases and Maria Santana, who translated three Spanish papers.

Contributors: SHS had the idea for the article. All authors took part in the planning and design of the study. SHS, DTE, RSP, and JV did the data collection. MS (listed in the acknowledgements) assisted in data collection from articles printed in Spanish. SHS carried out the statistical analyses. SHS,

\section{What is already known on this topic}

About one in four people do not adhere well to prescribed drug therapy

Poor adherence is considered a critical barrier to treatment success and remains an important challenge to healthcare professionals

\section{What this study adds}

Good adherence to drug therapy is associated with positive health outcomes

The observed association between adherence to placebo and mortality supports the premise of a healthy adherer effect, where adherence to drug therapy may be a surrogate marker for overall healthy behaviour 


\section{Research}

DTE, SRM, RSP, RTT, and JAJ had access to the data and participated in the interpretation of the data. SHS wrote the first draft of the paper. SHS provided leadership for the study and is guarantor.

Funding: None.

Competing interests: None declared.

1 DiMatteo MR. Variations in patients' adherence to medical recommendations: a quantitative review of 50 years of research. Med Care 2004;42:200-9.

2 Miller NH, Hill M, Kottke T, Ockene IS. The multilevel compliance challenge: recommendations for a call to action. A statement for healthcare professionals. Circulation 1997:95:1085-90.

3 Morris LS, Schulz RM. Patient compliance-an overview. J Clin Pharm Ther 1992;17:283-95

4 Donovan JL. Patient decision making. The missing ingredient in compliance research. Int J Technol Assess Health Care 1995;11:443-55.

5 Ellis S, Shumaker S, Sieber W, Rand C. Adherence to pharmacological interventions. Current trends and future directions. The Pharmacological Intervention Working Group. Control Clin Trials 2000;21:S218-25.

6 Osterberg L, Blaschke T. Adherence to medication. N Engl J Med 2005:353:487-97.

7 DiMatteo MR, Giordani PJ, Lepper HS, Croghan TW. Patient adherence and medical treatment outcomes: a meta-analysis. Med Care 2002;40:794-811.

8 Czajkowski SM, Chesney MA, Smith AW. Adherence and the placebo effect. In: Shumaker SA, Schron EB, Ockene JK, eds. The handbook of health behavior change. New York: Springer, 1990:515-34.

9 McDermott MM, Schmitt B, Wallner E. Impact of medication nonadherence on coronary heart disease outcomes. A critical review. Arch Intern Med 1997;157:1921-9.

10 Hays RD, Kravitz RL, Mazel RM, Sherbourne CD, DiMatteo MR, Rogers WH, et al. The impact of patient adherence on health outcomes for patients with chronic disease in the medical outcomes study. J Behav Med 1994:17:347-60.

11 In: Higgins JPT, Green S, eds. Cochrane handbook for systematic reviews of interventions 4.2.5 [updated May 2005]. www.cochrane.dk/cochrane/handbook/hbook.htm (accessed 3 Apr 2006)

12 Shumaker SA, Schron EB, Ockene JK. The handbook of health behavior change. New York: Springer, 1990.

13 Cramer JA, Spilker B. Patient compliance in medical practice and clinical trials. New York: Raven, 1991.

14 Myers LB, Midence K. Adherence to treatment in medical conditions. Australia: Harwood Academic, 1998

15 Cramer JA. A systematic review of adherence with medications for diabetes. Diabetes Care 2004;27:1218-24.

16 Fogarty L, Roter D, Larson S, Burke J, Gillespie J, Levy R. Patient adherence to HIV medication regimens: a review of published and abstract reports. Patient Educ Coun 2002;46:93-108.

17 Simoni JM, Frick PA, Pantalone DW, Turner BJ. Antiretroviral adherence interventions: a review of current literature and ongoing studies. Top HIV Med 2003;11:185-98.

18 Cohen JA. A coefficient of agreement for nominal scales. Educ Psychol Meas 1960;20:37-46.

19 Landis JR, Koch GG. The measurement of observer agreement for categorical data Biometrics 1977;33:159-74.
20 DerSimonian R, Laird N. Meta-analysis in clinical trials. Control Clin Trials 1986;7:17788.

21 Higgins JP, Thompson SG, Deeks JJ, Altman DG. Measuring inconsistency in meta-analyses. BMJ 2003;327:557-60.

22 Tobias A. Assessing the influences of a single study in meta-analysis. Stata Tech Bull 1999;47:15-7.

23 Echt DS, Liebson PR, Mitchell LB, Peters RW, Obias-Manno D, Barker AH, et al. Mortality and morbidity in patients receiving encainide, flecainide, or placebo. The cardiac arrhythmia suppression trial. N Engl J Med 1991;324:781-8.

24 Moher D, Schulz KF, Altman D. The CONSORT statement: revised recommendation for improving the quality of reports of parallel-group randomized trials. JAMA 2001;285:1987-91.

25 Boudes P. Drug compliance in therapeutic trials: a review. Control Clin Trials 1998;19:257-68

26 Haynes RB, Dantes R. Patient compliance and the conduct and interpretation of therapeutic trials. Control Clin Trials 1987;8:12-9.

27 Efron B, Feldman D. Compliance as an explanatory variable in clinical trials. J Am Stat Assoc 1991;86:9-26.

28 Weintraub M. Intelligent noncompliance with special emphasis on the elderly. Contemp Pharm Pract 1981;4:8-11.

29 Conrad P. The meaning of medications: another look at compliance. Soc Sci Med 1985:20:29-37.

30 Ciechanowski PS, Katon WJ, Russo JE. Depression and diabetes: impact of depressive symptoms on adherence, function, and costs. Arch Intern Med 2000;160:3278-85.

31 Rudd P. In search of the gold standard for compliance measurement. Arch Intern Med 1979;139:627-8.

(Accepted 21 April 2006)

doi $10.1136 /$ bmj. 38875.675486 .55

Faculty of Pharmacy and Pharmaceutical Sciences, University of Alberta,

Edmonton, AB, Canada T6G 2N8

Scot H Simpson assistant professor

Institute of Health Economics, Edmonton, $\mathrm{AB}$

Dean T Eurich research associate

Janice Varney librarian

Division of Internal Medicine, Department of Medicine, Faculty of Medicine and Dentistry, University of Alberta

Sumit R Majumdar associate professor

Rajdeep S Padwal assistant professor

Division of Cardiology, Department of Medicine, Faculty of Medicine and Dentistry, University of Alberta

Ross T Tsuyuki professor

Department of Public Health Sciences, Faculty of Medicine and Dentistry, University of Alberta

Jeffrey A Johnson professor

Correspondence to: S H Simpson ssimpson@pharmacy.ualberta.ca 